\title{
The Breast Implant Rupture Warranty: What Is It Really Worth?
}

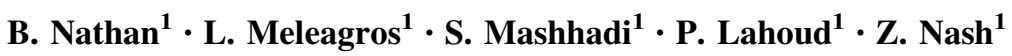

Received: 5 April 2015/Accepted: 24 July 2015/Published online: 25 August 2015

(C) Springer Science+Business Media New York and International Society of Aesthetic Plastic Surgery 2015

Level of Evidence $V$ This journal requires that authors assign a level of evidence to each article. For a full description of these Evidence-Based Medicine ratings, please refer to the Table of Contents or the online Instructions to Authors www.springer.com/00266.

To the Editor,

We recently encountered a rupture of an Allergan Natrelle implant model TSF that was implanted 4 years previously. This was confirmed by ultrasound prior to the revision. The manufacturer's microscopic and mechanical analysis was "consistent with a sharp instrument" and as such not eligible for credit under their warranty scheme. The patient took legal action against the primary implanting surgeon.

A number of important issues must here be considered. The rupture warranty of most breast implants provides replacement of the implants in case of a manufacturing fault plus a contribution towards a secondary operation. The most generous warranty is therefore worth less than $£ 1000$ namely the cost of replacement implants and a contribution towards the cost of revisional surgery.

As most implants will be found iatrogenically damaged [1], it may therefore be that the rupture warranty offered by implant manufactures while providing patients with the now fashionable "peace of mind" factor is more beneficial to the manufacturer than it is to the patient. The terms of the warranty must be carefully studied and fully explained to the patient as part of the surgical informed consent. It may also be that a court would consider the date of knowledge of the rupture and not the date of the first operation as the limitation period for initiating legal action against the primary implanting surgeon.

Given that the overall rupture rate of breast implants is about $10 \%$ in 10 years [2] is it time to consider independent analysis of explanted prostheses? We invite our histopathologist colleagues to extend their microscopic and laboratory skills to analyze ruptured implants. We hope that breast implant manufacturers would co-operate in this matter and accept independent verification. The wisdom of returning ruptured implants to the manufacturer is in question. We welcome further research and debate from colleagues.

\section{Compliance with Ethical Standards}

Conflict of interest The authors have no conflict of interest to disclose.

\section{References}

1. Handel N, Garcia ME, Wixtrom R (2013) Breast implant rupture: causes, incidence, clinical impact, and management. Plast Reconstr Surg 132:1128-1137

2. Spear SL, Murphy DK (2014) Natrelle round silicone breast implants: core study results at 10 years. Plast Reconstr Surg 133:1354-1361

\author{
B. Nathan \\ bassem@doctors.net.uk \\ Riverside Hospital, London, UK
}

